\section{Clostridium difficile and its Toxins}

Toxigenic strains of Clostridium difficile are presently recognized as possible causative agents of antibiotic-associated diarrhoea or colitis in humans. There is evidence that the pathogenic effect of $C$. difficile is mediated by at least two distinct toxins $(1-4)$ which are unrelated immunologically (5): firstly, an enterotoxin (known as toxin A) which is active in the rabbit ileal loop, Chinese Hamster Ovary (CHO) cell elongation, rabbit skin vascular permeability and suckling mouse tests and secondly, a cytotoxin (known as toxin B) which is toxic to cultured mammalian cells (HeLa, human lung fibroblasts WI-38, rat hepatoma MHC and others), but is negative in test models for enterotoxigenicity.

To contribute more information to the biological profile of toxin $\mathrm{A}$ in comparison with toxin $\mathrm{B}$, we have investigated the activity of these bacterial products in the platelet aggregation test (PAT), an assay system thgt represents a suitable procedure for defining the mechanism of action of some enterotoxins. Since platelet aggregation is known to be influenced by compounds which modify the intracellular level of c-AMP, we $(6,7)$, like others $(8,9)$, have previously shown that ADP-induced platelet aggregation can be inhibited by enterotoxins, e.g. cholera toxin and cholera-like toxins, which increase the intraplatelet cAMP. In its response to enterotoxins acting via adenylate-cyclase stimulation, the behaviour of the PAT is similar to tissue culture models. Our study was designed to examine preparations of toxin A and toxin B from $C$. difficile kindly provided by Nadine $M$. Sullivan, Virginia Polytechnic Institute and State University, Blacksburg, VA, U.S.A. The preparations were endotoxin-free by the Limulus assay, and not cytotoxic to human platelets by the lactic-dehydrogenase $(\mathrm{LDH})$ test. The protein concentrations were 0.8 and $0.2 \mathrm{mg} / \mathrm{ml}$, respectively. In our assay, two different preparations of toxin A inhibited the ADPinduced platelet aggregation (the inhibition was abrogated by heating the preparation), whereas two different preparations of toxin $B$ were inactive. The observations reported here are clearly preliminary and their interpretation is limited by the small number of experiments performed. Despite these restrictions, there are some similarities between $C$. difficile toxin A and cholera or cholera-like toxins with respect to the effects observed in the PAT: toxin B is inactive in this model (as previously demonstrated by other bioassays for enterotoxins).

Several questions will have to be clarified before these findings can be confirmed: Are the effects of toxin A neutralized by antitoxin A, cholera antitoxin or heat-labile (LT) antitoxin? (Investigations dealing with these problems are in progress.) Based on the results presented here, we feel certain statements can be made. Since current procedures for detecting enterotoxins are often timeconsuming and technically difficult to use routinely, we believe that a simple, sensitive and reproducible assay (such as the PAT) may contribute to determining the enterotoxigenicity of $C$. difficile isolates and may eventually provide information as to a possible mechanism responsible for disease production. The findings presented here are compatible with a mechanism resembling that of enterotoxins which stimulate the adenylate-cyclase system. Since chlorpromazine $\left(10^{-4} \mathrm{M}\right)$ inhibits the effect of toxin $A$ in our model, it seems reasonable to assume that an activation of guanylate-cyclase does not occur. Finally, our results may provide additional information to differentiate the biological profile of the bacterium's major toxins more clearly.

\section{Fumarola, G. Miragliotta}

\section{Acknowledgements}

Support for these studies was provided in part by a grant (no. 83.00652.52) from the Consiglio Nazionale delle Ricerche (C.N.R.), 1983, Progetto Salute dell'Uomo, Controllo Malattie Infettive. We would like to thank Dr. Sam T. Donta, Chief, V.A. Medical Center, University of Connecticut Health Center Hospitals, for his helpful comments and suggestions.

\section{Literature}

1. Banno, Y., Kobayashi, T., Watanabe, K., Vero, K., Nuzawa, Y.: Two toxins (D-1 and D-2) of Clostridium difficile causing antibioticassociated colitis: purification and some characterization. Biochem. Int. 2 (1981) 629-635.

2. Liely, D. M., Lockwood, D. E., Richardson, S. H., Wilkins, T. D.: Biological activity of toxin $\mathrm{A}$ and $\mathrm{B}$ of Clostridium difficile. Infect. Immun. 35 (1982) 1147-1150.

3. Donta, S. T., Sullivan, N., Wilkins, T. D.: Differential effects of Clostridium difficile toxins on tissue-cultured cells. J. Clin. Microbiol. 15 (1982) 1157-1158.

4. Sullivan, N. M., Pellett, S., Wilkins, T. D.: Purification and characterization of toxin $\mathbf{A}$ and $\mathbf{B}$ of Clostridium difficile. Infect. Immun. 35 (1982) 1032-1040.

5. Libby, J., Wilkins, T. D.: Production of antitoxin to two toxins of Clostridium difficile and immunological comparison of the toxins by cross-neutralization studies. Infect. Immun. 35 (1982) 374-376.

6. Fumarola, D.: Platelet aggregation: an assay system for some enterotoxins that stimulate adenylate cyclase system? Haematologica 62 (1977) 108-109.

7. Fumarola, D., Miragliotta, G.: Platelet Aggregation Test (PAT): an assay system to evaluate enterotoxins. 83rd Annual Meeting of the American Society for Microbiology, New Orleans, March 6-11, 1983, abstract B 99 .

8. Girshovich, E. S., Mats, A. N., Tabachnick, A. L.: Effect of enterotoxins of Vibrio cholerae and $E$. coli upon aggregation of human thrombocytes induced by adenosine diphosphate. Westn. Akad. Med. Nauk SSRR 1 (1976) 59-64.

9. Richter, B., Tschäpe, H., Kühn, H.: Die Hemmung der Thrombozyten-Aggregation durch LT-Enterotoxine - ein Schnelltest zur Untersuchung klinischer Durchfälle. Dt. Gesundh.-Wesen 33 (1978) 1094-1097.

D. Fumarola, G. Miragliotta, Institute of Medical Microbiology, University of Bari, Policlinico, Piazza Giulio Cesare 4, I-70124 Bari. 